\title{
Determinantes de la felicidad en los administradores: una investiga- ción realizada en las farmacias del Grupo Difare en Ecuador
}

Determinants of Managers' Happiness: A Research Carried Out in the Pharmacies of the Difare Group in Ecuador

Determinantes da felicidade nos administradores: uma pesquisa realizada nas farmácias do Grupo Difare no Equador

\author{
Juan Pablo López \\ Isidro Fierro ${ }^{* \star}$
}

Fecha de recibido: 13 de octubre de 2014

Fecha de aprobado: 3 de marzo de 2015

Doi: dx.doi.org/10.12804/rev.univ.empresa.29.2015.08

Para citar este artículo: López, J. P.; \& Fierro, I. (2015). Determinantes de la felicidad en los administradores: una investigación realizada en las farmacias del Grupo Difare en Ecuador. Universidad \& Empresa, 17(29), 181-211. Doi: dx.doi.org/10.12804/rev.univ.empresa.29.2015.08

\section{RESUMEN}

El bienestar subjetivo es un indicador de la felicidad y de la calidad de vida de los individuos. Refleja la experiencia de los seres humanos de acuerdo a condiciones de vida como buenas

* Coach Ontológico Corporativo Certificado AICO en HPI Guayaquil, Ecuador. Green Belt six sigma, TBL Group Consulting, Guayaquil, Ecuador. Ingeniero en Ciencias Empresariales de la Universidad Espíritu Santo (UEES), Jefe Comercial Megafarmacias S. A. Portoviejo, Ecuador. Correo electrónico: Juanpablo.lopez@megafarmacias.com

** Estudiante de Doctorado en Ciencias de la Dirección de la Universidad del Rosario (Bogotá, Colombia), Magíster en Administración de Empresas, MBA de la Universidad de Lleida (Cataluña, España) y Magíster en Biología de la Universidad del Estado de California (Fresno, Estados Unidos). Decano de la Facultad de Estudios Internacionales de la Universidad de Especialidades Espíritu Santo-uees-. Correo electrónico: isfierro@uees.edu.ec 
relaciones sociales, prosperidad económica y salud. Las personas felices tienden a ser más saludables, mejores ciudadanos y empleados más productivos. En esta investigación se aborda la teoría y los diversos estudios que analizan diferentes determinantes de la felicidad. Se toma como terreno de campo al Grupo Difare, una cadena de retail farmacéutico en Ecuador. Se realizó una encuesta que permitió determinar el nivel de bienestar subjetivo y de otros nueve indicadores: 1) bienestar psicológico, 2) felicidad laboral, 3) espiritualidad, 4) salud, 5) apoyo social, 6) afectos positivos, 7) bienestar material, 8) balance trabajo-vida y 9) acceso a educación, cultura y recreación. Se evidencia, como resultado, qué dominios afectan más la felicidad de los trabajadores y se sugiere en cuáles se debería trabajar más.

Palabras clave: bienestar psicológico, bienestar subjetivo, espiritualidad, felicidad laboral, salud.

\section{ABSTRACT}

Subjective well-being (SwB) is an indicator of happiness and quality of life of individuals. It reflects the experience of human beings according to their living conditions, such as good social relations, economic prosperity and good health. Happy people tend to be healthier, better citizens and more productive employees. In this research, the theory and different studies that analyze determinants of happiness were taken into consideration. The Difare Group, a pharmaceutical retailer in Ecuador, was chosen to be the place for the fieldwork. A survey was carried out to determine the swB and nine other indicators: 1) psychological well-being, 2) happiness at work, 3) spirituality, 4) health, 5) social support, 6) positive affections, 7) material well-being, 8) work-life balance, and 9) access to education, culture and recreation. The result showed the domains that affect the happiness of workers most and the ones in which they should work most.

Keywords: Psychological well-being, subjective well-being, spirituality, happiness at work, health.

\section{RESUMO}

O bem-estar subjetivo é um indicador da felicidade e da qualidade de vida dos indivíduos. Reflete a experiência dos seres humanos de acordo a condições de vida como boas relações sociais, prosperidade económica e saúde. As pessoas felizes tendem a ser mais saudáveis, melhores cidadãos e empregados mais produtivos. Nesta pesquisa se aborda a teoria e os diversos estudos que analisam diferentes determinantes da felicidade. Se toma como terreno de campo ao Grupo Difare, uma cadeia de retail farmacêutico no Equador. Realizou-se um inquérito que permitiu determinar o nível de bem-estar subjetivo e de outros nove indicadores: 1) bem-estar psicológico, 2) felicidade laboral, 3) espiritualidade, 4) saúde, 5) apoio social, 6) afetos positivos, 7) bem-estar material, 8) balanço trabalho-vida e 9) acesso à educação, cultura e recreação. Se evidencia, como resultados, que domínios afetam mais a felicidade dos trabalhadores e se sugere em quais se deveria trabalhar mais.

Palavras-chave: bem-estar psicológico, bem-estar subjetivo, espiritualidade, felicidade laboral, saúde. 


\section{INTRODUCCIÓN}

Ser feliz es una aspiración universal. Desde los primeros estudios filosóficos, la felicidad ha sido un tema de gran importancia. Aristóteles definió la felicidad como "el bien supremo del hombre, estipulando que para acceder a esta se necesita cultivar nuestras virtudes y vivir de acuerdo a ellas" (La Sociedad, 2014). En el siglo XVII el filósofo francés Blaise Pascal escribió: "Todos los hombres buscan la manera de ser felices. Esto no tiene excepción, es el motivo de todos los actos de todos los hombres, hasta de aquellos que se ahorcan" (Planells, 1988). En los tiempos modernos, la creciente cantidad de libros de autoayuda presentes en las librerías y la existencia de cada vez más estudiosos enfocados en desarrollar este tema reafirman la necesidad de entender el concepto de felicidad. Esto con el fin de volverlo más tangible y alcanzable.

A pesar de su importancia, la felicidad fue dejada de lado por la psicología y los estudios sociales durante mucho tiempo. Estos se enfocaron principalmente en aspectos negativos y patológicos del comportamiento humano (Seligman, 2000). Solo hace unos veinte años inicia de manera muy visible una tendencia en el estudio científico de las cualidades positivas de los individuos, de las variables que hacen a un individuo feliz y de los efectos que esto puede tener en otros aspectos de la vida (Seligman, 2000).

Gracias a estos estudios entendemos hoy que monitorear la felicidad como indicador no solo es importante por el hecho de que este refleje de algún modo la calidad de vida que experimentan las personas, sino porque también existe una causalidad en otra dirección. En efecto, si se observa de otro modo, es posible percatarse de que las personas felices muestran ser más saludables, amigables, productivas y mejores ciudadanos que los individuos que no lo son (De Neve, Diener, Tay, \& Xuereb, 2013).

Basados en la anterior premisa, y en el entendimiento de que indicadores económicos como el producto interno bruto (РIB) no son funcionales para interpretar los niveles de bienestar de los ciudadanos, algunos países han tenido la iniciativa de incorporar el índice de felicidad. Esto con el fin de medir su eficacia gubernamental y tener una visión más integral que les permita implementar políticas que viabilicen y faciliten el desarrollo sostenible de un buen vivir para sus ciudadanos.

Uno de los primeros países en desarrollar este modelo fue Bután. Esta 
nación en 1929 registró en su código legal que si un gobierno no crea felicidad para su gente, el propósito de este no existe (Ura, 2011). Por su parte, en 1972 el rey IV de Bután, su majestad Jigme Singye Wangchuck, ideó por primera vez un índice de felicidad nacional bruta (IFNB) para medir el bienestar de sus ciudadanos y destacó que este es más importante que el índice de producción y consumo de bienes y productos PIB. Adicionalmente, mencionó que todas las políticas y planes de desarrollo estarían orientadas a promover los índices de felicidad bruta (The Center of Bhutan Studies, 2010). El IFNB representa un concepto holístico. Su objetivo principal es proponer un marco alternativo para el desarrollo de las naciones basado en nueve dominios: 1) bienestar, 2) estándares de vida, 3) salud, 4) cultura, 5) educación, 6) vitalidad comunitaria, 7) buen gobierno, 8) uso del tiempo balanceado y 9) integración ecológica (The Center of Bhutan Studies, 2010).

Alineados con la tendencia indicada, y entendiendo la importancia de investigar las causas de la felicidad y sus beneficios, un grupo de expertos del Instituto de la Tierra, en la Universidad de Columbia, recopiló los estudios más importantes en el campo de la felicidad y desarrolló en 2012 el primer índice mundial de la felicidad. Este tuvo su segunda edición en 2013. A través de esta iniciativa dicha institución ha contribuido al debate acerca de cuáles deberían ser los objetivos en materia de desarrollo sostenible para el periodo 2015-2030. Estos estudios constituyen una valiosa herramienta para que los Estadosy gobiernos puedanadoptar las mejores políticas y proyectos posibles con el fin de que estas resulten en un incremento del bienestar general de sus naciones.

De hecho, se considera que las empresas deberían alinearse a este modelo de desarrollo. Sería necesario entender entonces cuáles son las causas que fomentan la felicidad en los empleados de una organización para poder realizar un diseño de políticas y programas orientados a la maximización del bienestar de sus colaboradores. Esto podría generar un beneficio mutuo, pues diferentes estudios demuestran que los individuos más felices tienen índices de productividad más altos (Lyubomirsky, 2005).

Dados los antecedentes mencionados, los objetivos básicos de esta investigación son 1) explorar las definiciones conceptuales de la felicidad, revisando la literatura más relevante del tema y 2) identificar cuáles son las principales causales que hacen variar los niveles de 
felicidad entre un individuo y otro, considerando para ello, como terreno de investigación, la población de administradores de las farmacias del Grupo Difare en Ecuador.

\section{REVISIÓN DE LA LITERATURA \\ 1.1. Definición de bienestar subjetivo}

Filósofos e investigadores han utilizado diferentes teorías para definir el bienestar subjetivo (Diener, Kesebir, \& Lucas, 2008). Ellos la han dividido, en particular, en dos tendencias: la primera es la teoría hedónica. Su premisa básica consiste en que es necesario maximizar las sensaciones placenteras. Por su parte, la segunda, la teoría eudemónica, se enfoca en el crecimiento espiritual basado en el cultivo de la ética (Deci, 2008). En múltiples estudios psicológicos actuales, la tendencia hedónica se ejemplifica en los métodos que utilizan diferentes investigadores sociales para medir la felicidad cuantificando el balance de afectos positivos. Es decir que las experiencias de sensaciones placenteras como alegría, interés, amor y respeto sean mayores a las experiencias de sensaciones negativas como la tristeza, el dolor, la angustia y el miedo (Watson, Clark, \& Carey, 1988).

En contraste a la teoría hedónica, la tendencia eudemónica, desarrolla el concepto de felicidad considerando que una vida feliz es una basada en hacer lo moralmente correcto y virtuoso y cultivando mente, cuerpo y alma (Guariglia, 2002). Es posible encontrar otros autores con posiciones similares como, por ejemplo, Abraham Maslow (1970) con el concepto de autorrealización, Ryff y Singer (1996) con la visión de bienestar psicológico y Ryan y Deci (2000) con la teoría de la autodeterminación (Peterson, 2005). El énfasis de la teoría eudemónica es que los individuos deben perseguir objetivos significativos y desarrollar sus talentos y habilidades para beneficios superiores (Peterson, 2005).

Podemos entender que la felicidad basada en el hedonismo, es decir, la constante búsqueda de placer, sería insostenible sin un propósito significativo y la búsqueda de autorrealización, de la misma manera, si esta no se desarrolla a partir de una vida virtuosa con propósitos nobles. La felicidad, además, sería difícil de mantener si no se tienen experiencias placenteras.

Cuando se miden aspectos hegemónicos y eudemónicos del bienestar se encuentra que estos se encuentran directamente correlacionados. Ambos se complementan muy bien para determinar la felicidad de un individuo (Kashdan, Biswas Diener, 
\& King, 2008). Sin embargo, la mayoría de autores coincide en que la conceptualización más adecuada que se le ha dado a la felicidad, dada su naturaleza subjetiva, es la de "bienestar subjetivo" (Mayers, 1995). El bienestar subjetivo tiene el objetivo de reflejar la felicidad de las personas y su propia percepción de qué tan satisfactorias, deseables y reconfortantes son sus vidas (Diener \& Tay, 2012).

De acuerdo con Diener, Kesebir y Tov (2009), el bienestar subjetivo tiene tres grandes constituyentes: uno interno, cognitivo, que es la satisfacción con la vida, y dos externos, referidos a la experiencia de emociones positivas o la ausencia de emociones negativas. La satisfacción con la vida es considerada por estos autores como los juicios generales de la vida propia. Los afectos positivos constituyen la frecuencia de emociones placenteras como alegría, orgullo y éxtasis, con la ausencia de afectos negativos como enfado, estrés, depresión o envidia (Diener, Suh, Lucas, \& Smith, 1999).

En resumen, una persona con un alto nivel de bienestar o felicidad subjetiva es aquella que está satisfecha en general con su vida, experimenta emociones positivas la mayor parte del tiempo y raramente siente emociones negativas (Diener, 1999). Para poder elaborar un modelo de felicidad es importanteentendercuálesson sus causantes. En la siguiente sección de esta investigación se exploran estos conceptos.

\subsection{Determinantes de la felicidad}

En esta sección se exploran los diferentes dominios que afectan la felicidad de las personas. Nos basamos para esto, inicialmente, en el modelo planteado por Lyubomirsky (2005). En este se propone que la felicidad de un individuo tiene tres componentes: 1) el factor genético o el valor de referencia, 2) las circunstancias externas y 3) las actividades deliberadas. Este modelo es notablemente similar al del profesor Seligman, en el cual se establece que el nivel de felicidad es la suma de 1) las precondiciones personales hacia el bienestar de cada individuo, 2) las circunstancias externas o demográficas y 3) los factores de control personal o la decisión personal, como relaciones sociales, objetivos y tiempo libre (Seligman, 2000).

Según diferentes estudios, se determina que aproximadamente el $50 \%$ de nuestra felicidad depende de la herencia genética que tenemos (Lyubomirsky, 2008). Este resultado se obtiene analizando los niveles en esta materia de gemelos idénticos y 
gemelos fraternos, en donde la felicidad de los gemelos idénticos es muy similar entre ellos (Tellegen et al., 1988).

De acuerdo con estos estudios, y con la teoría de la adaptación hedónica, los acontecimientos importantes en la vida de un individuo, como un ascenso laboral, ganar la lotería o perder a un ser querido, solo afectarían la felicidad del individuo por un tiempo hasta que este vuelva a su valor referencial genético (Bagenstos \& Schlange, 2007). Estudios anteriores muestran que la felicidad de personas que ganaron la lotería o perdieron una extremidad volvió al punto previo antes del acontecimiento después de un período de ajuste de aproximadamente un año (Brickman, 1978).

El segundo determinante son las circunstancias externas o demográficas del individuo. Es decir, la región, la cultura o el país en el que se reside. También se consideran factores demográficos como la edad, el género y la etnia, e importan igualmente la historia particular, como la existencia de traumas de la niñez o las experiencias familiares. Por último, elementos vinculados con el estatus social como los ingresos, las afiliaciones religiosas, el estado civil y la ocupación, entre otros, deben ser también contemplados.
La evidencia sugiere que el bienestar subjetivo es más alto en personas que son casadas, se involucran en grupos sociales de apoyo, tienen mejores ingresos, poseen un estatus social y laboral alto, creen estar sanos y viven en países prósperos e independientes (Myers, 1995). Sin embargo, una vez las necesidades psicológicas son satisfechas, estas variables externas solo afectan entre un $8 \%$ y $15 \%$ la felicidad total de los individuos (Boehm \& Lyubomirsky, 2009). Una de las teorías que explica este fenómeno es la teoría de adaptación hedónica. Esta enuncia que los individuos vuelven a sus niveles originales de felicidad después de un tiempo de acomodación a nuevas circunstancias (Frederick \& Loewenstein, 1999). Así, por ejemplo, las personas que ganan la lotería tienen un incremento en su felicidad que dura aproximadamente seis meses. Ello hasta volver al nivel que tenían antes de ganar el premio. De la misma manera, aunque en otro tipo de situaciones extremas, personas que sufren accidentes en los que pierden extremidades de su cuerpo, sufren una caída en su nivel de felicidad, pero después de aproximadamente seis meses vuelven también al punto en donde su felicidad estaba justo antes del accidente (Lucas, 2007).

El tercer determinante es quizás el más importante, puesto que puede 
ser manipulado con nuestra actividad intencional, este lo constituyen las actividades diarias o rutinarias. Estas son acciones normales que tienen un propósito específico y una regularidad. Se convierten en hábitos de comportamiento y definen al individuo (Lyubomirsky \& Sheldon, 2005). Así, por ejemplo, hacer ejercicios todos los días para bajar de peso o tomar clases de francés en preparación para un viaje son tipos de actividades que requieren un nivel de compromiso y que han sido probadas en el sentido de que proveen un empuje sostenido a los niveles de felicidad.

Esta serie de actividades y hábitos tiene un efecto de aproximadamente el $40 \%$ de determinación en la felicidad (Lyubomirsky et al., 2005). Las prácticas en donde se encontró relación entre su aplicación y el bienestar subjetivo de los individuos son hábitos de gratitud, amabilidad, perdón, optimismo, espiritualidad, escoger y perseguir las metas propias, nutrir las relaciones sociales personales, buscar oportunidades para experimentar 'flujo' o 'absorción' y, finalmente, hacer ejercicio físico y meditación (Lyubomirsky, 2008).

Seligman (2002) sugiere que una auténtica felicidad es facilitada también al desarrollar hábitos en donde se practiquen virtudes como la cu- riosidad, el juego, el humor, la tolerancia y la esperanza. Ryan, Huta \& Deci (2008), por su parte, sugieren que la felicidad puede ser incrementada cuando un individuo busca conseguir objetivos intrínsecos basados en sus creencias personales como crecimiento personal, relaciones sociales, comunidad y salud, en lugar de objetivos extrínsecos basados en estándares sociales como riqueza, fama, imagen y poder. Esto implica actuar con sentido y conciencia, en lugar de ser manipulado por necesidades fisiológicas (Ryan, 2008).

Tiene sentido pensar que las actividades diarias que realizamos predicen gran parte de nuestra felicidad, pues traen consigo consecuencia en nuestro trabajo, salud, comunidad y relaciones sociales. En esta investigación se analizó el efecto de nueve diferentes aspectos de la felicidad general en los administradores de las farmacias del Grupo Difare. Estas son: bienestar psicológico, afectos positivos, apoyo social, felicidad laboral, salud, espiritualidad, balance vida-trabajo y acceso a educación, cultura y recreación. En la siguiente sección se analiza la teoría vinculada a estos constructos.

\subsection{Bienestar psicológico}

Los estudios de la medicina tradicional — física o psicológica — se han 
enfocado por lo general en la ausencia de enfermedades y no en la presencia de lo positivo. De hecho, la literatura psicológica tradicional define a un individuo psicológicamente funcional como la persona que no sufre de enfermedades mentales, ansiedad o depresión (Ryff, 1995). Sin embargo, tener bienestar psicológico es más que carecer de estrés y de problemas mentales. Una persona psicológicamente sana es un individuo que posee, entre otros, aspectoscomo autoaceptación, autonomía, autocontrol, relaciones sociales positivas, sentido de propósito y significado en la vida, además de una sensación de desarrollo personal continuo y dominio ambiental (Ryff, 1995).

De acuerdo a Ryff (1989) y Ryff y Singer (1996), la 'autoaceptación' puede ser definida como la percepción positiva propia, teniendo conciencia de las fortalezas y debilidades. Un individuo con 'autonomía', por su parte, es aquel con la capacidad de juzgar sus propias acciones bajo sus propios estándares, sin buscar aprobación de los demás. Las 'relaciones sociales positivas' se conceptualizan como la capacidad de relacionarse y crear lazos de comunicación y conectividad profunda con amigos y parejas amorosas. El 'sentido de propósito' es la sensación de legado y trascendencia, en particu- lar la capacidad de generar impactos duraderos en la sociedad. El 'desarrollo personal' se establece en la medida en que los objetivos del individuo son alcanzados. Finalmente, el 'dominio ambiental' es la capacidad de adaptar los hábitats $\mathrm{o}$ ambientes de acuerdo a las propias necesidades (Ryff \& Singer, 2008).

Se puede afirmar que un individuo, cuando ha logrado dominar los aspectos mencionados, tiene un alto bienestar psicológico (Ryff et al., 2008). En una exhaustiva investigación realizada por Diener y Tay (2012) se concluye que individuos con un alto bienestar psicológico tienen mejores resultados en salud, niveles de ingreso y desempeños laborales que sus pares con bajo nivel de bienestar psicológico. Este, entonces, es valioso no solo porque es una herramienta para medir el bienestar subjetivo de forma directa, sino que, adicionalmente tiene consecuencias positivas en los diferentes aspectos de la vida de las personas (Diener et al., 2008).

\subsection{Afectos positivos y negativos (la escala de afecto positivo y negativo -PANAS-)}

Esta se basa en un modelo con dos dimensiones independientes: afectos positivos y afectos negativos (Ostir, 2000). La primera hace referencia a 
estados emocionales de bienestar en donde el individuo reporta sentimientos de entusiasmo, alegría y felicidad. La segunda hace referencia a estados emocionales de estrés o malestar en donde el individuo reporta sentimientos de frustración, tristeza y miedo (Diener, 1984).

A través de diferentes estudios se demuestra la correlación nula -0 cercana a la misma - de estas dos dimensiones (Watson, 1998). Adicionalmente, se encuentra una alta relación de los afectos positivos con la satisfacción de vida o bienestar subjetivo. Esto quiere decir que, mientras más emociones positivas y menos negativas experimente un individuo, más elevada será la tendencia en sus niveles de felicidad (Lyubomirsy, 2005). Fredericson \& Losada (2005) demuestran además que los individuos que reportan un alto bienestar o un estado de "florecimiento" experimentan un factor de 2,9 o más emociones positivas por cada negativa. También se demuestra la influencia que tienen los afectos positivos en diferentes dominios deseables de la vida como salud, relaciones sociales, satisfacción con la existencia, resilencia y manejo de situaciones estresantes (Folkman, 1997). En el caso de los afectos negativos se observa una tendencia a tener síntomas de depresión, ansiedad o problemas de salud en general (Watson, 1988).

\subsection{Apoyo social}

Contar con amigos y familiares en momentos difíciles o para compartir situaciones de alegría ha probado ser un determinante muy importante al momento de evaluar el bienestar y la felicidad de los individuos (Huppert, 2009). Psicólogos sugieren que el apoyo social promueve la felicidad, influenciando la emoción, la cognición y el comportamiento que crea emociones positivas (Gallagher, 2008). Además, tiene una fuerte influencia en la salud de los individuos y está directamente relacionada con su satisfacción laboral (Stansfeld, Shipley, Head, Fuhrer, \& Kivimaki, 2013).

En un estudio llevado a cabo por Stansfield, que encuestó a 5182 individuos ingleses para medir sus niveles de apoyo social y si estos pueden predecir el nivel de bienestar subjetivo y de satisfacción laboral, se encontró que las personas con altos niveles de apoyo emocional reportaron también altos niveles de bienestar subjetivo, así como elevados niveles de satisfacción laboral (Stansfeld et al., 2013). Ello puede deberse a factores como el hecho de que amigos y familiares, proveedores del apoyo social, soporten constantemente el crecimiento personal y compartan consejos relacionados con el trabajo, la vida amorosa y la 
salud (Gallant, 2007). Estos actores se recomiendan entre sí prácticas médicas exitosas, escuchan mutuamente sus necesidades, ríen juntos y se comprometen a actividades significativas (Gallant, 2007). Al involucrarse en la vida del otro, de manera recíproca, los amigos pueden mitigar la sensación de soledad y depresión con tan solo el hecho de "estar ahí" (Green, 2001).

\subsection{Felicidad laboral}

Desde hace aproximadamente diez años, los estudios en el campo de felicidad han crecido de manera importante, creando con ello una vasta cantidad de investigación empírica acerca de los procesos y causales de la felicidad en las personas. Uno de los hallazgos más aceptados es la influencia que tiene el trabajo en la felicidad del individuo (Fisher, 2010). Por ejemplo, la felicidad de un individuo se ve afectada negativamente cuando queda desempleado y su nivel es recuperado solamente cuando vuelve a emplearse (Clark, 2008).

Para definir la felicidad en el trabajo es necesario ir más allá de considerar simplemente la satisfacción laboral. Un constructo válido para medir los niveles de felicidad en el trabajo incluye satisfacción laboral, engagement (compromiso) en el trabajo, flujo, desarrollo personal, auto- nomía, impacto en la sociedad, autorrealización y afectos positivos mientras se trabaja (Fisher, 2010). En todos los niveles se encuentra una gran impacto de la felicidad en el trabajo a nivel personal y corporativo (Fisher, 2010).

A pesar de que estos constructos tengan definiciones muy particulares existe una relación estrecha entre ellos. Esto hace que al conceptualizarlos y medirlos se superpongan (Xanthopoulou, 2012). Dichos constructos comparten el hecho de que todos se refieren a percepciones positivas o experiencias positivas en el trabajo(Bakker \& Oerlemans, 2011).

Bakker y Oerlemans (2011) usan el modelo circumplejo (Russell, 1980) para explicar las diferentes formas de felicidad en el trabajo. Lo hacen analizando qué tan activados o alertas se encuentran los individuos de acuerdo con su nivel de placer. En su investigación estos autores consideran la satisfacción laboral, el engagement en el trabajo y la felicidad.

La satisfacción laboral, por su parte, es definida como una emoción positiva que resulta de la percepción de los individuos hacia su trabajo, en general, y las experiencias positivas o negativas que tienen mientras lo realizan (Locke, 1970). La satisfacción laboral se establece como un 
estado de bienestar que se caracteriza por presentar altos niveles de satisfacción y una activación baja (Bakker \& Oerlemans, 2011).

Esto puede ser explicado al observar que los individuos que consideran positivo su trabajo no necesariamente están buscando de manera activa esa condición (Xanthopoulou, 2012). La felicidad en lo que se hace también es un estado positivo, pero más activo que la satisfacción laboral. La felicidad se caracteriza por un alto nivel de satisfacción y moderado nivel de activación. Así, un empleado feliz es menos activo que un empleado entusiasta, pero más activo que un empleado satisfecho (Bakker \& Oerlemans, 2011). De la misma manera, los empleados con un alto nivel de engagement tienen un elevado nivel de activación y de satisfacción (Bakker, 2008).

\subsection{Salud}

Definida por la Organización Mundial de la Salud (oms) como "un estado completo de bienestar físico, mental y social, y no solo la ausencia de afecciones o enfermedades" (World Health Organization -WHO-, 1948). Diferentes especialistas señalan que este concepto, con más de seis décadas sin modificación alguna, no refleja verdaderamente su significado (Jadad, 2013). El Doc- tor Jadad, fundador del Centro de Innovación para una Salud Global de Canadá, señaló en el sexagésimo aniversario de la oms que posiblemente nadie podría alegar tener un bienestar social, mental, físico y social completo y que una revisión a la definición era necesaria (Jadad, 2013). Esto motivó a la Organización Holandesa para la Investigación en Salud y Desarrollo a convocar una reunión de La Haya donde se discutió esta definición y se llegó a la propuesta de conceptualizar a la salud como la habilidad de adaptarse y autorregularse cuando se enfrentan desafíos físicos, mentales y sociales (Huber et al., 2011).

$\mathrm{Al}$ entender la salud así, como una habilidad de adaptarse y autorregularse, emerge la posibilidad de que la salud y las enfermedades puedan convivir. Es decir, una persona puede tener enfermedades y ser "sana" al mismo tiempo (Carel, 2008). Diferentes estudios muestran autorreportes de salud en donde los individuos indican que su salud es "buena", "muy buena" o "excelente", esto, por ejemplo, a pesar de tener enfermedades crónicas (Terner, 2011). Adicionalmente, se encuentra que los individuos que reportan su salud como "mala" tienen el doble de riesgo de mortalidad que los que reportaron su salud como "excelente" (DeSalvo, Bloser, Reynolds, He J., 2006). Pro- 
fundizando estos estudios, una investigación australiana demuestra que el $62 \%$ de las personas que viven con cáncer diagnosticado como incurable consideran su salud "buena" o "muy buena". Este autorreporte es, de hecho, un predictor importante de sus posibilidades de sobrevivir (Shadbolt, Barresi \& Craft, 2002).

Jadad (2013) reflexiona acerca de la mortalidad diciendo que esta nos recuerda que no es suficiente con agregar más años a nuestra vida, sino que es talvez más importante agregar más vida a nuestros años. Punset (2005), en un sentido similar, indica que el desafío de la humanidad no es tanto determinar si hay vida después de la muerte, sino si en realidad hay "vida" antes de esta.

Para responder las preguntas de cómo tener una vida completa y sana, problablemente los determinantes más importantes, pero a la vez más descuidados que guíen hacia la obtención de una respuesta sean el amor y la felicidad (Jadad., 2013).

\subsection{Espiritualidad}

La espiritualidad se ha convertido en el foco de muchos estudios de salud mental en los últimos años. Sin embargo, todavía es un concepto difícil de definir. Myer (2000) la define como "la conciencia de un ser o fuer- za que trasciende los aspectos materiales de la vida y provee un profundo sentido de totalidad y conexión con el universo" (p. 253). Existen también otras definiciones, como "un proceso de autoiluminación" (Nash, 2001, p.17) o "la búsqueda interna para el máximo desarrollo personal a través de la participación en el misterio de trascender" (Delbecq, 1999, p. 345).

Es posible observar entonces la dificultad de definir la espiritualidad, en particular por ser algo intangible y ampliamente subjetivo. Sin embargo, es posible encontrar un vínculo fuerte entre la espiritualidad, la felicidad, el desempeño laboral y la rentabilidad. (Karakas, F, 2010). El profesor Karakas, analizando 140 trabajos, encuentra que la relación entre la espiritualidad de las personas y su desempeño laboral se puede dar principalmente de tres formas: 1) fomentando el bienestar y la calidad de las personas, 2) proveyendo un sentido de propósito y significado al trabajo y 3) brindando a los empleados un sentido de conectividad y comunidad. Como hemos visto en los párrafos anteriores, todas estas variables se relacionan con la productividad.

\subsection{Bienestar material}

Diferentes estudios han probado que el dinero no tiene una influencia im- 
portante en la felicidad de las personas después de que sus necesidades básicas, fisiológicas y de seguridad son cubiertas (Diener \& Oishi, 2000). $\mathrm{El}$ indicador de bienestar material busca identificar si los individuos están atravesando por angustias financieras, si su ingreso es suficiente para cubrir sus necesidades y si están satisfechos con su calidad de vida (The Happiness Initiative, 2014). Es importante notar que este indicador no solamente está afectado por el nivel de ingresos de los individuos, sino por su habilidad para administrar el dinero y no incurrir en gastos mayores.

\subsection{Acceso a educación, cultura y actividades al aire libre}

Este indicador refleja la satisfacción de los encuestados respecto a las posibilidades que tienen de acceder a educación formal, actividades culturales, artísticas y al deporte (The Happiness Initiative, 2014). A través de diferentes investigaciones se demuestra que las personas que pueden recrearse a través de diferentes actividades muestran niveles de felicidad subjetiva más altos (Argyle, 2003). Esto puede ser explicado principalmente, entre otros aspectos, por el hecho de que los individuos que se exponen a estas actividades tienen más posibilidades de crear relaciones saludables y sostenibles (Fredrickson, 2001).

\subsection{Balance entre tiempo libre y trabajo}

Este indicador reporta la satisfacción o insatisfacción que tienen los encuestados al considerar de cuánto tiempo disponen para realizar actividades por fuera del trabajo (The Happiness Initiative, 2014). El balance de tiempo entre tiempo libre y trabajo contribuye al bienestar subjetivo, puesto que permite a los individuos tener más experiencias con emociones positivas en diferentes aspectos de la vida (Seligman, 2000). Para que un individuo se sienta completo y autorrealizado es necesario que busque el desarrollo de todas las facetas de su vida (Maslow, 2013).

\subsection{Efectos de la felicidad}

La felicidad no está relacionada con el éxito solo por el hecho de que este haga que las personas se sientan más felices. La teoría prueba que emociones positivas como la alegría, el optimismo y la gratitud inducen a las personas a actuar de una forma que promueve la construcción de recursos y la búsqueda de resultados (Elliot, 2002).

Las emociones se construyen a través de la percepción sensorial de 
un evento. Este proceso puede ser consciente o subconsciente $\mathrm{y}$, dependiendo del estímulo, desencadena una cascada de respuestas químicas internas. El proceso, además, suele terminar en una respuesta física externa (Fredrickson, 2001). Las emociones positivas liberan ideas y acciones, mejoran la concentración y la creatividad y ayudan a los individuos a mejorar sus relaciones sociales y a ser más flexibles (Fredrickson, 2001).

Las personas felices, al parecer, acostumbran construir o interpretar eventos de manera diferente a las menos felices. Se abstienen de hacer comparaciones sociales que puedan minimizarlos, son persistentemente optimistas y tienen estrategias diferentes para enfrentar conflictos en comparación con sus pares menos felices (Lyubomirsy, King, \& Diener, 2005). Los individuos felices también seleccionan exponerse a ambientes y relaciones que generen o faciliten una mayor felicidad posterior (Lyubomirsky, 2008).

Al estudiar los beneficios de tener un estado mental positivo, diferentes estudios muestran las ventajas de la felicidad (Achor, 2010). En un meta-análisis de 225 estudios, los profesores Lybomirsky, King \& Diener (Lyubomirsky S. K., 2005) encontraron importante evidencia de una causalidad entre la felicidad - en sus formas de satisfacción, estados emocionales positivos y complacencia con la vida - con diferentes aspectos como la salud, el desempeño, los ingresos, los éxitos matrimoniales y las relaciones sociales.

En el mencionado estudio se pudo encontrar que los empleados más felices tienen en promedio $31 \%$ más de productividad, generan un $37 \%$ más de ventas y tres veces más creatividad (Lyubomirsky et al., 2005). En un estudio realizado en una compañía de seguros, Seligman determinó también que los niveles de optimismo son predictores del éxito de las ventas en mucho mayor medida que lo es el coeficiente intelectual (Seligman, 2011). Los indicadores de bolsa de valores muestran que las mejores empresas para trabajar presentan un retorno superior que otras que no lo son en este mismo contexto. De hecho, comparando a las mejores cien empresas para trabajar de Fortune con el S\&P 500 y el Russell 3000 se encuentra que estas tienen un retorno dos veces mayor que el promedio del mercado (Great Place to Work, 2013).

\section{METODOLOGÍA}

Los datos obtenidos para la investigación se recogieron a través una encuesta online realizada en el mes 
de julio de 2013 a 265 administradores de las farmacias del Grupo Difare. La encuesta constituyó un censo completo a nivel nacional, alcanzando a todos los administradores de las cadenas de farmacias del Grupo.

El diseño de la investigación que se aplicó fue cuantitativo y cualitativo. Se realizaron preguntas tanto cualitativas, para determinar condiciones demográficas, como cuantitativas, para encontrar el nivel de bienestar subjetivo y dominios como salud, apoyo social, bienestar psicológico, felicidad laboral, afectos positivos y espiritualidad. Se realizó un análisis correlacional y de regresión lineal para poder establecer una relación entre estos y el bienestar subjetivo.

Las escalas utilizadas fueron del 1 al 7. Siendo 7 el calificativo superlativo y 1 la peor calificación posible. Se establecieron rangos del 1 al 3 para calificar a los individuos con bajo nivel de felicidad, del 3 al 5 para un nivel de felicidad medio y del 5 al 7 para los individuos con un nivel de felicidad alto (Gallup Healthways, 2013).

El bienestar subjetivo se mide regularmente por escalas en donde el individuo registra su percepción acerca de qué tan feliz es. La escala que se utilizó fue la de felicidad subjetiva de Lyubomirsky (1999). La encuesta de felicidad subjetiva tiene cuatro preguntas en donde se registra qué tan feliz se considera el individuo en general y qué tan feliz se considera en comparación con los demás. Esto provee una idea bastante clara de su nivel de felicidad general (Lyubomirsky, 1999).

Para medir el bienestar psicológico de los encuestados se utilizó la escala de satisfacción con la vida (Pavot \& Diener, 1993) y la escala de afecto positivo y negativo (Watson et al., 1988). Estas son encuestas muy sencillas y directas. La escala de satisfacción tiene cinco preguntas enfocadas a la satisfacción global del individuo con su vida en general (Pavot \& Diener, 1993). La encuesta de afecto positivo-negativo intenta registrar cómo se sintieron los individuos en las últimas semanas, exponiendo estados de ánimos positivos como inspirado, emocionado y fuerte y estados de ánimo negativos como culpable, triste y temeroso (Watson et al., 1988).

Por tratarse de un autorreporte, los índices de felicidad subjetiva están sujetos a la influencia de externalidades temporales y de estados de ánimo momentáneos (Diener et al., 2008). Sin embargo, la validación de las escalas ha demostrado una elevada confiabilidad en los resul- 
tados al 1) tener un alto grado de correlación entre estas, 2) coincidir con reportes realizados por otros investigadores, 3) no evidenciar variaciones entre edades y sexo y 4) mostrar que su variación en el tiempo es mínima (Diener et al., 2009).

Para medir la felicidad laboral se utilizó la encuesta de felicidad en el trabajo desarrollada por Marcs (2012) que se basa en el modelo de bienestar desarrollado por la New Economics Fundation de la Oficina de Ciencias del gobierno británico (Marcs, 2012). Este modelo reconoce que la felicidad en el trabajo es un sistema fluido con múltiples factores que se interconectan como:

- La experiencia general en el trabajo: Que responde a cómo se sienten los trabajadores y que mide los afectos positivos y negativos.

- El desempeño en el trabajo: En donde se registra autonomía, sensación de progreso, relaciones en el trabajo y libertad de expresar la identidad.

- Sistema empresarial: Que hace emerger las percepciones acerca de qué tan satisfechos se encuentran los empleados con el ambiente físico, el sistema de gestión, el diseño del trabajo y el valor social de la empresa.
Estos factores, finalmente, se conectan con los recursos personales de empleado como felicidad personal, resilencia, vitalidad y equilibrio vida personal-trabajo (Marcs, 2012).

Para el resto de dominios, es decir, apoyo social, salud y espiritualidad, se utilizó la encuesta desarrollada por el Laboratorio de Bienestar y Personalidad de la Universidad de San Francisco (The Happiness Initiative, 2014). Para medir el nivel de apoyo social, los administradores encuestados reportaron su percepción acerca de poder contar con amigos o familiares en momentos difíciles. En salud los sujetos reportaron sus niveles de energía, deporte, impedimentos físicos y cómo se sentían en este aspecto en general, y, finalmente, en lo relativo a la espiritualidad, indicaron si tenían creencias religiosas y las practicaban (The Happiness Initiative, 2014).

\section{RESULTADOS}

\subsection{Variables cualitativas}

Globalmente considerados los resultados son bastante positivos. Estos muestran que el $75 \%$ de los administradores de las farmacias de Grupo Difare tiene un alto nivel de felicidad, el $24 \%$, media y el $1 \%$, baja (ver figura 1). La distribución obtenida se muestra en la figura 2. 
Figura 1. Gráfico de barras relativo a la felicidad de los administradores de las farmacias del Grupo Difare

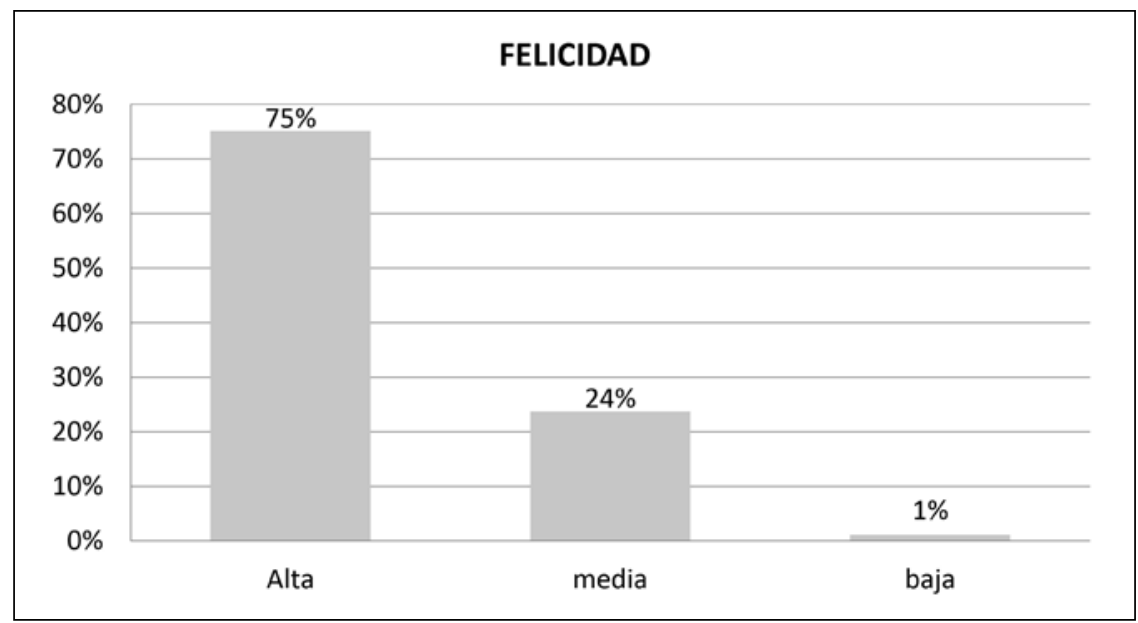

Fuente: Elaboración propia.

Figura 2. Distribución felicidad administradores cadena de farmacias Grupo Difare

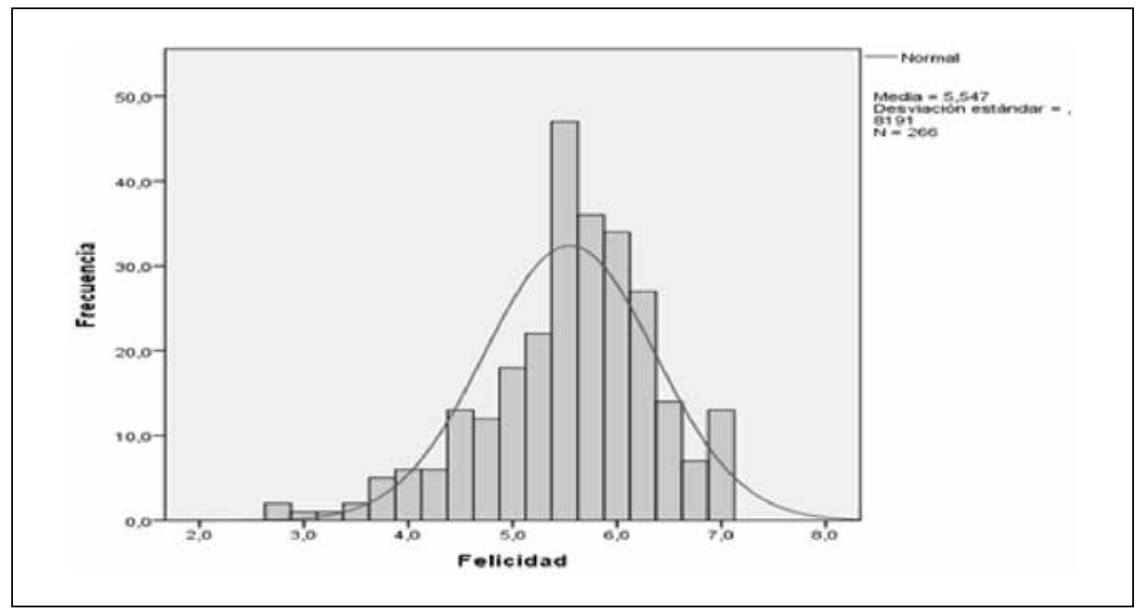

Fuente: Elaboración propia.

Se identifica, en general, un com- nivel elevado de felicidad, siendo portamiento estable en la felicidad los individuos entre 19 y 26 años, al considerar los diferentes rangos sin embargo, los menos felices en de edades. En todos se identifica un promedio (ver figura 3). 
Figura 3. Felicidad de acuerdo al rango de edades (Puntación promedio, siendo 7 la más alta y 1 la más baja)

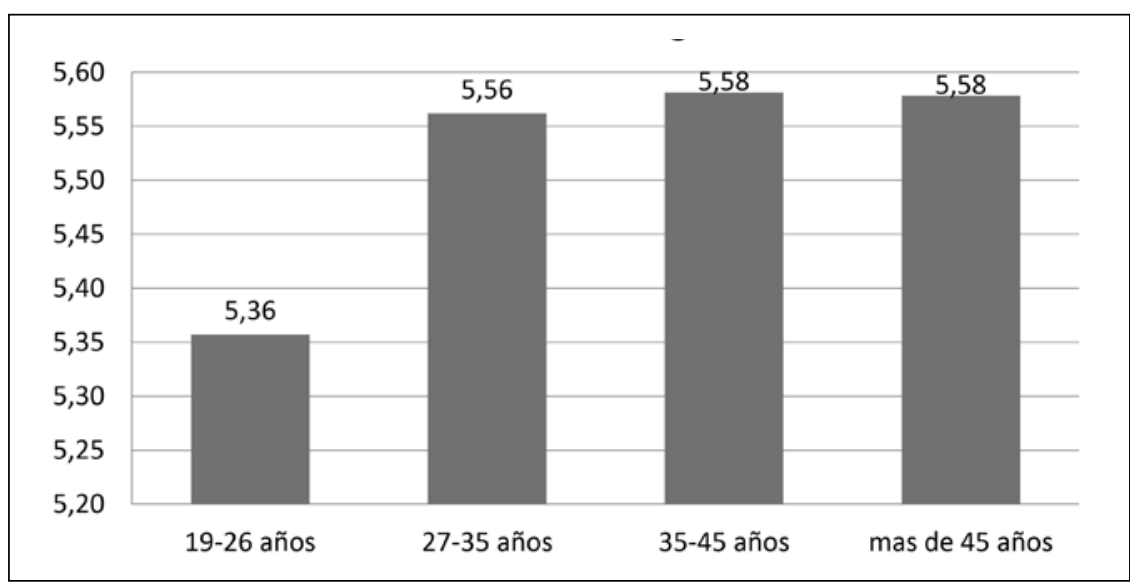

Fuente: Elaboración propia.

El bienestar de los administradores tampoco cambia sustancialmente en función de las ciudades (ver figura 4) en las que se encuentran, ni del jefe regional (ver figura 5), ni de los años trabajando o el tiempo de traslado al trabajo (ver figura 6).

Figura 4. Felicidad de acuerdo a las ciudades (Puntación promedio, siendo 7 la más alta y 1 la más baja)

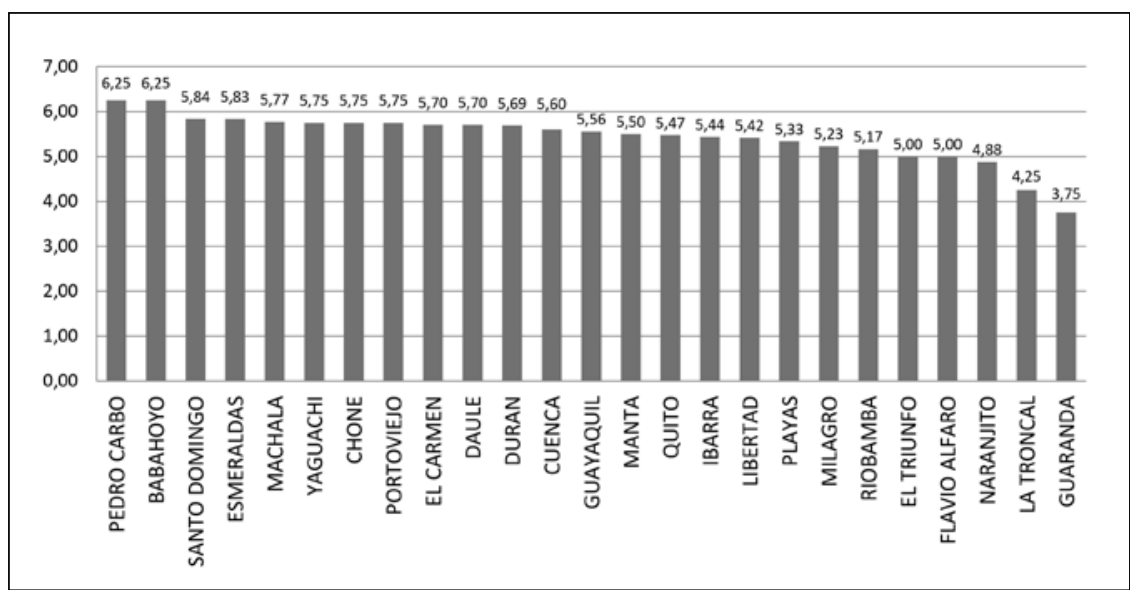

Fuente: Elaboración propia. 
Figura 5. Felicidad de acuerdo al jefe regional (Puntación promedio, siendo 7 la más alta y 1 la más baja)

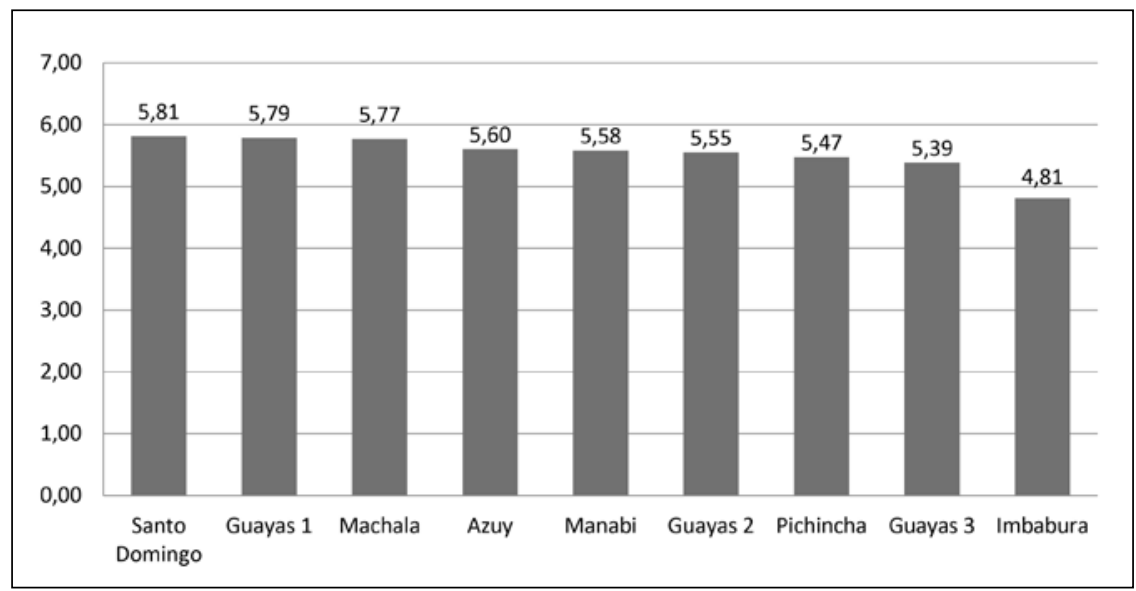

Fuente: Elaboración propia.

Figura 6. Felicidad de acuerdo a los años de trabajo (Puntación promedio, siendo 7 la más alta y 1 la más baja)

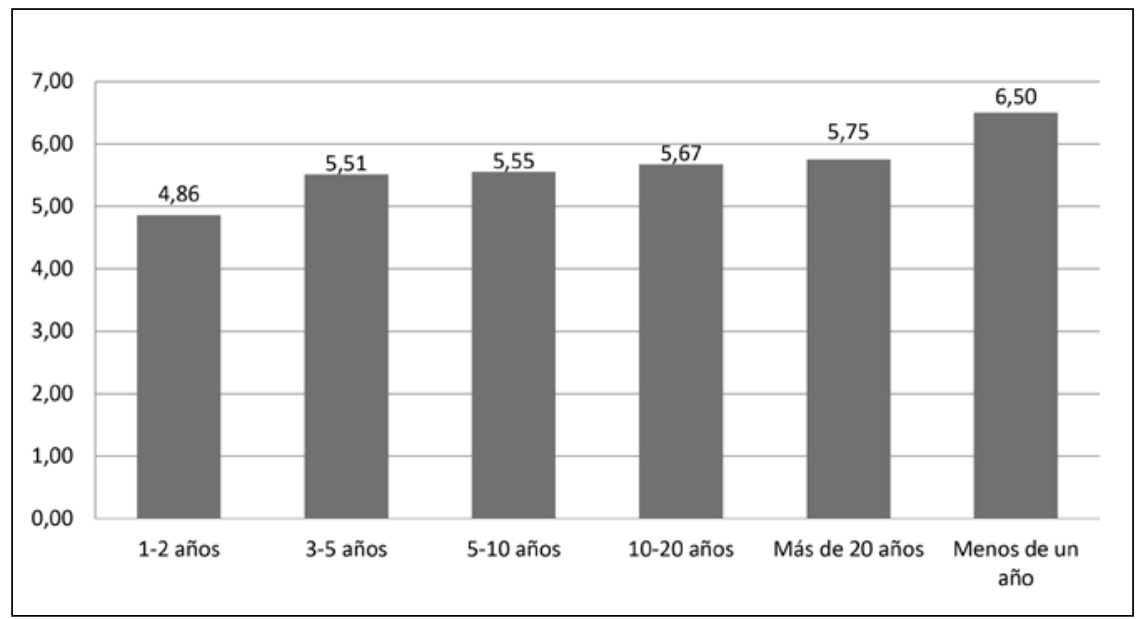

Fuente: Elaboración propia.

Sin embargo, se observa un nivel de en otras palabras, en aquellas que felicidad mayor en las personas que han alcanzado un grado de escolaritienen un nivel de estudio superior, dad más elevado (ver figura 7). 
Figura 7. Felicidad de acuerdo al nivel de estudio (Puntación promedio, siendo 7 la más alta y 1 la más baja)

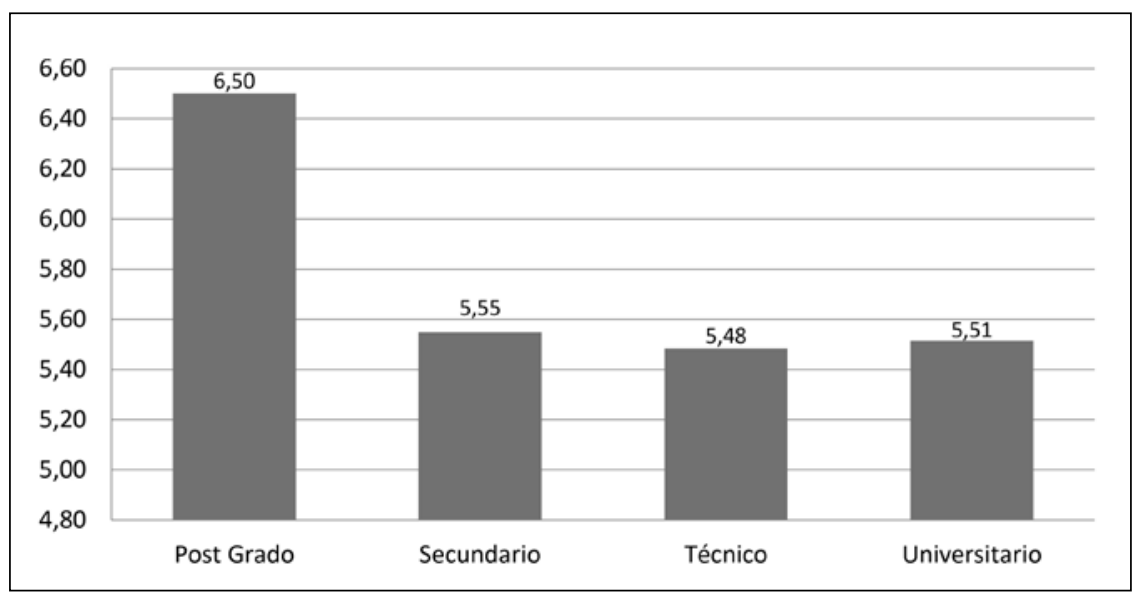

Fuente: Elaboración propia.

En lo que concierne al estado civil, ser "viudos(as)" (ver figura 8). En lo se observa que son más felices quie- que respecta al género, por su parte, nes declaran ser "divorciados(as)" y se observa que las mujeres son más menos felices aquellos que indican felices que los hombres (ver figura 9).

Figura 8. Felicidad de acuerdo al estado civil (Puntación promedio, siendo 7 la más alta y 1 la más baja)

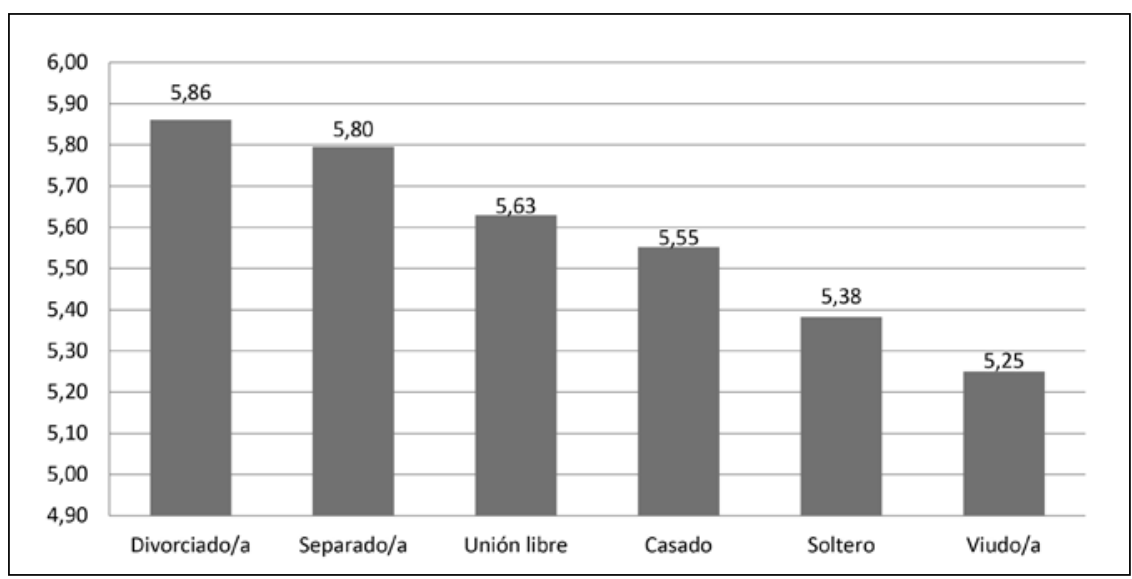

Fuente: Elaboración propia. 
Figura 9. Felicidad de acuerdo al género (Puntación promedio, siendo 7 la más alta y 1 la más baja)

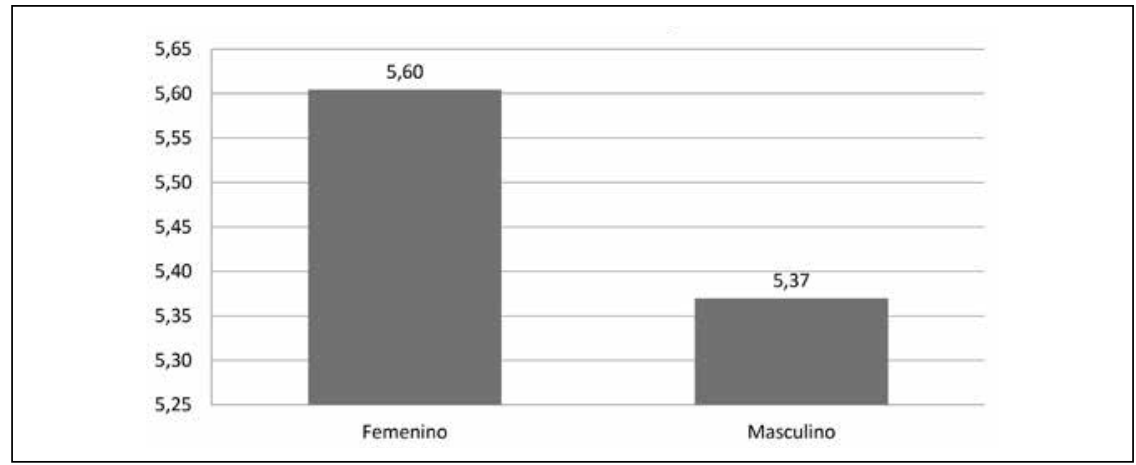

Fuente: Elaboración propia.

En efecto, las mujeres son general- divorciadas son más felices que los mente más felices que los hombres. hombres divorciados (ver figuras 10 Esto sin importar su edad (ver figu- y 11). Esto puede deberse, probablera 10) o estado civil (ver figura 11). mente, a que, a diferencia de lo que Sin embargo, en lo que respecta a sucede cuando estos procesos de esta última variable, se encuentra realizan de manera informal, las reque los hombres separados son más particiones de bienes, por ejemplo, felices que las mujeres separadas. tienden a ser más equitativas cuando Curiosamente, además, las mujeres son el resultado de un trámite legal.

Figura 10. Felicidad de acuerdo al género y las edades (Puntación promedio, siendo 7 la más alta y 1 la más baja)

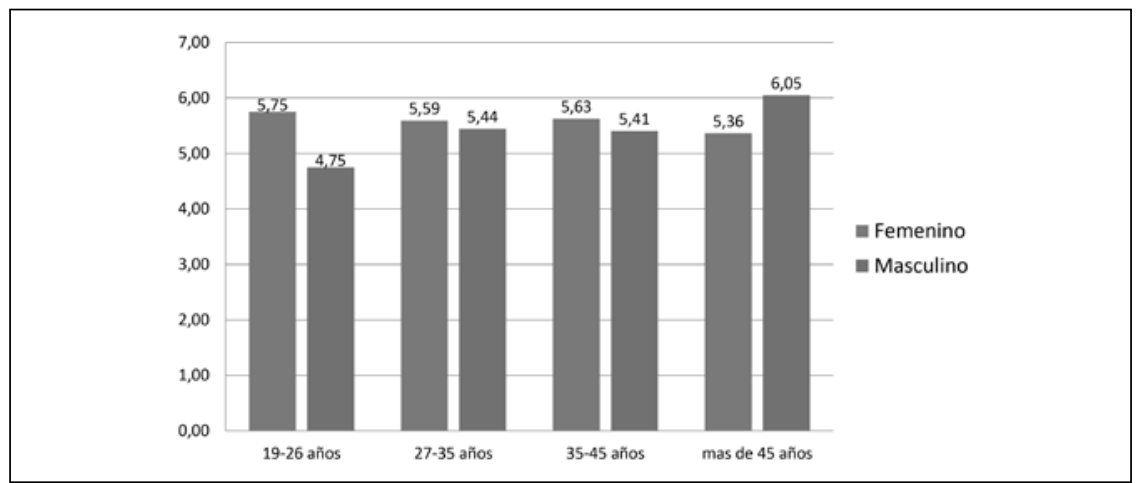

Fuente: Elaboración propia. 
Figura 11. Felicidad de acuerdo al género y el estado civil

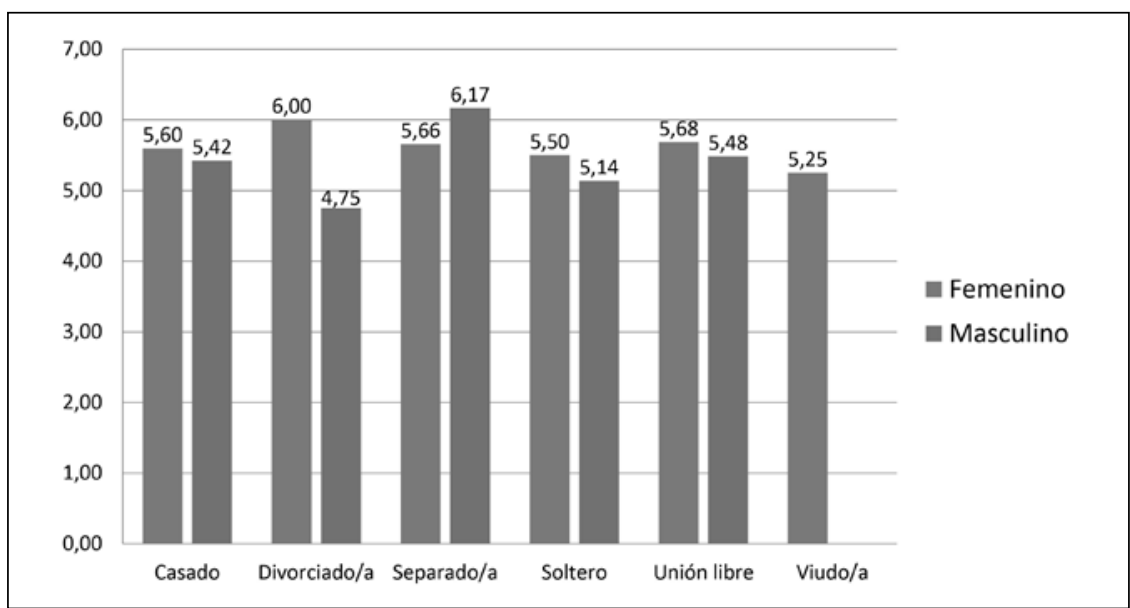

Fuente: Elaboración propia.

\subsection{Variables cuantitativas}

Se encontró que el bienestar psicológico, la felicidad en el trabajo, el apoyo social, el bienestar material, el balance entre trabajo y vida, la espiritualidad, el acceso a la cultura y la educación, los afectos positivos y la salud tienen una alta correlación con la felicidad (ver tabla 1).

Tabla 1. Correlaciones para la variable felicidad

\begin{tabular}{|c|c|c|c|c|c|c|c|c|c|c|c|c|}
\hline \multicolumn{13}{|c|}{ Correlaciones } \\
\hline & & & 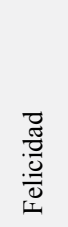 & 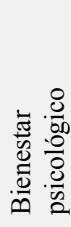 & 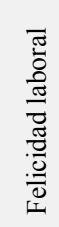 & 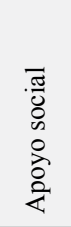 & 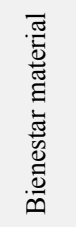 & 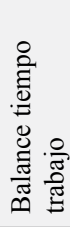 & 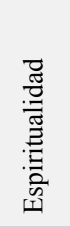 & 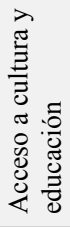 & 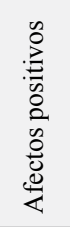 & 茎 \\
\hline \multirow{3}{*}{ 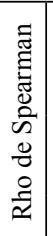 } & \multirow{3}{*}{ 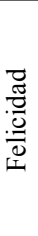 } & $\begin{array}{l}\text { Coeficiente } \\
\text { de } \\
\text { correlación }\end{array}$ & 1.000 &, $546^{* *}$ & , 466" &, $380^{* *}$ &, $328^{* * *}$ &, $333^{* *}$ & ,291** &, $252^{* * *}$ & ,232** &, $174^{* * *}$ \\
\hline & & $\begin{array}{c}\text { Sig. } \\
\text { bilateral }\end{array}$ & & .000 & .000 & .000 & . 000 & .000 & .000 & . 000 & .000 & .005 \\
\hline & & $\mathrm{N}$ & 265 & 265 & 265 & 265 & 265 & 265 & 265 & 265 & 265 & 265 \\
\hline
\end{tabular}

${ }^{* *}$ La correlación es significativa en el nivel 0,01 (2 colas)

Fuente: Elaboración propia. 
Sin embargo, se identificó también la felicidad en el trabajo (con 10\%), que el predictor más influyente de la el bienestar material y la espiritualifelicidad es el bienestar psicológico, $\quad \mathrm{dad}(\operatorname{con} 6 \%)$ y los afectos positivos con $75 \%$ de importancia. Le siguen (con 3\%) (ver figura 12).

Figura 12. Predictores de la felicidad

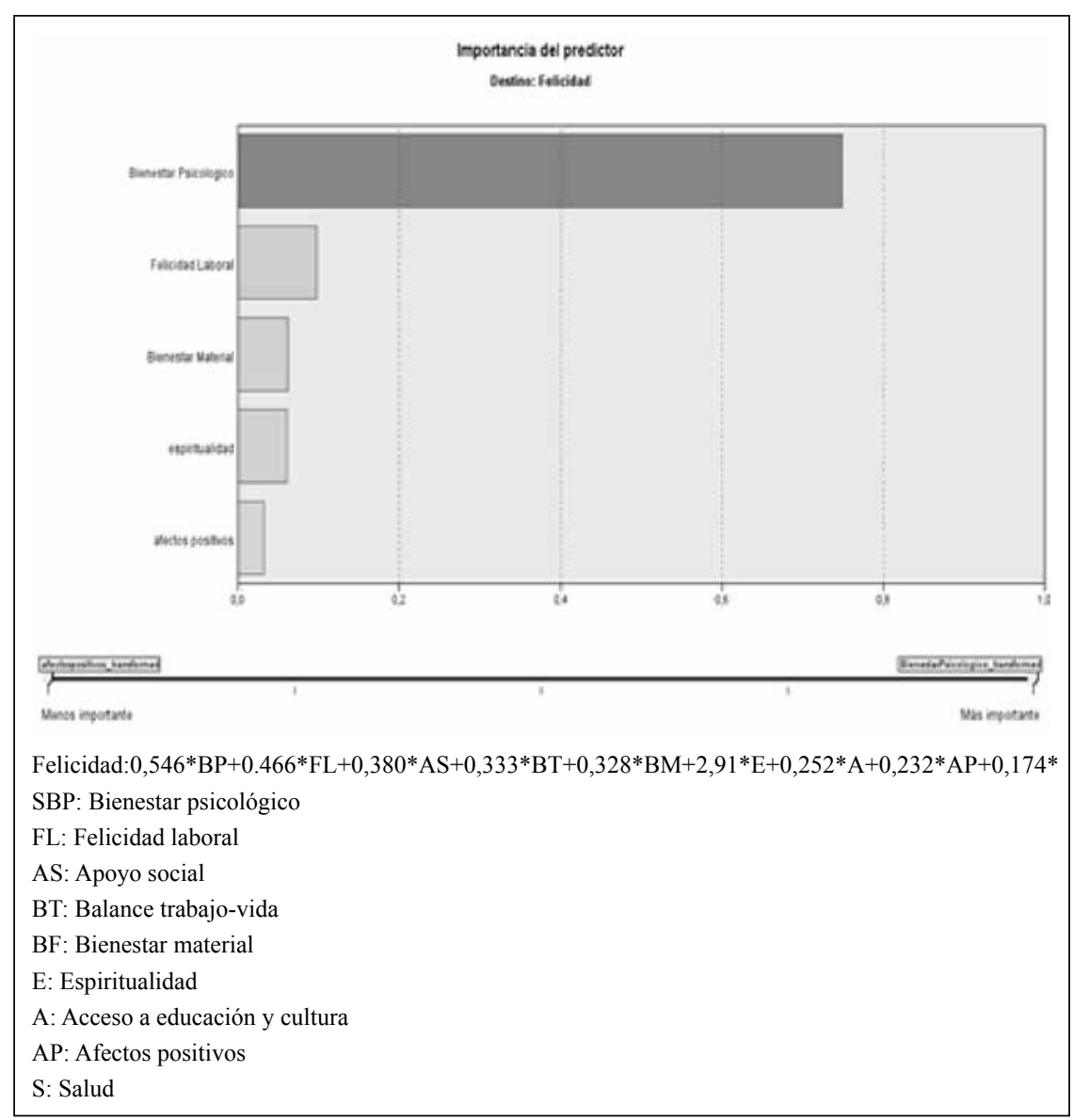

Fuente: Elaboración propia.

Los estadísticos descriptivos calcu- de la felicidad se presentan en la lados respecto a los determinantes tabla 2 : 
Tabla 2. Estadísticas descriptivas de los determinantes de la felicidad

\begin{tabular}{|l|c|c|c|c|c|c|}
\hline & $\mathrm{N}$ & Mínimo & Máximo & Media & $\begin{array}{c}\text { Desviación } \\
\text { estándar }\end{array}$ & Varianza \\
\cline { 2 - 8 } & Estadístico & Estadístico & Estadístico & Estadístico & Estadístico & Estadístico \\
\hline Apoyo social & 265 & 2,3 & 7,0 & $\mathbf{6 , 1 4 1}$ & 0,9394 & 0,882 \\
\hline $\begin{array}{l}\text { Bienestar } \\
\text { psicológico }\end{array}$ & 265 & 3,3 & 7,0 & $\mathbf{6 , 1 2 9}$ & 0,6214 & 0,386 \\
\hline Felicidad laboral & 265 & 2,7 & 6,7 & $\mathbf{5 , 7 2 1}$ & 0,6802 & 0,463 \\
\hline Afectos positivos & 265 & 1,2 & 7,0 & $\mathbf{5 , 7 1 8}$ & 1,0162 & 1,033 \\
\hline Bienestar material & 265 & 2,3 & 7,0 & $\mathbf{4 , 6 7 8}$ & 0,8208 & 0,674 \\
\hline Espiritualidad & 265 & 1,0 & 7,0 & $\mathbf{4 , 3 0 0}$ & 1,5502 & 2,403 \\
\hline $\begin{array}{l}\text { Balance tiempo- } \\
\text { trabajo }\end{array}$ & 265 & 1,0 & 7,0 & $\mathbf{4 , 3 0 0}$ & 1,4314 & 2,049 \\
\hline $\begin{array}{l}\text { Acceso a cultura } \\
\text { y educación }\end{array}$ & 265 & 1,0 & 7,0 & $\mathbf{3 , 8 5 8}$ & 1,4467 & 2,093 \\
\hline Salud & 265 & 2,0 & 6,8 & $\mathbf{3 , 7 5 7}$ & 0,7580 & 0,575 \\
\hline
\end{tabular}

Fuente: Elaboración propia.

Como se observa, el conjunto de los elementos considerados resulta ser, de un modo u otro y en diversos niveles, relevante para la felicidad. Al fin de cuentas, tal vez el desafío más importante para todos los seres humanos es descubrir cómo tener una vida más larga, sana, llena de amor $\mathrm{y}$, en general, feliz. Esto desde la primera inspiración, dada justo después del nacimiento, hasta la última espiración, justo antes de la muerte.

\section{CONCLUSIONES}

A través de los datos obtenidos es posible sugerir que los aspectos demográficos como la edad, el género, la distancia al trabajo, la ciudad o el tiempo trabajando en la compañía no afectan de manera sustancial la felicidad de los administradores de las farmacias del Grupo Difare. Sin embargo, de manera consecuente con los otros estudios expuestos en este trabajo respecto al tema, factores como bienestar psicológico, la felicidad en el trabajo y el balance entre trabajo y vida personal tienen una alta influencia al medir el bienestar subjetivo. Para futuros estudios es necesario hacer mediciones considerando aún más indicadores. Esto para encontrar patrones adicionales que puedan contribuir a crear un modelo cada vez más preciso acerca de la felicidad. 
Es posible observar que los indicadores de salud, acceso a la educación, actividades culturales y balance entre el trabajo y la vida personal son aquellos en los que los administradores de la cadena Difare tienen menor satisfacción (en promedio). Es aconsejable entonces buscar políticas y programas que propendan por mejorar en estos aspectos.

El factor determinante más influyente en la felicidad de los administradores de las farmacias del grupo Difare es el bienestar psicológico. Es recomendable entonces enfocar esfuerzos a la formación de los factores que promueven este indicador. Instruir a los colaboradores, por ejemplo, en psicología positiva puede crear una herramienta importante para avanzar hacia la construcción de una ventaja competitiva sostenible en el tiempo (Achor, 2010).

Las empresas requieren crear espacios en donde se fomenten las emociones positivas, el fortalecimiento de relaciones sociales y la creación de significado superior en el trabajo. Vale la pena considerar, finalmente, lo señalado por el doctor Aravin Vijayaraghavan: "No basta con la capacidad e inteligencia, sino con la alegría de hacer algo hermoso" (Vijayaraghavan, 2006).

\section{REFERENCIAS}

Achor, S. (2010). The happiness advantage: The seven principles of positive psychology that fuel success and performance at work. Nueva York: Broadway Books. Argyle, M. (1999). Causes and correlates of happiness. En D. Kahneman, E. Diener, \& N. Schwarz (Eds.). Well-being: The foundations of hedonic psychology ( $\mathrm{p}$. 353-373). Nueva York: Russell Sage Foundation.

Bagenstos, S. R., \& Schlange, M. (2007). Hedonic damages, hedonic adaptation, and disability. Vanderbilt Law Review, 60(3), pp. 745-797.

Bakker, A. B., \& Oerlemans, W. (2011). Subjective well-being in organizations. En K. S. Cameron \& G. M. Spreitzer (Eds.), The Oxford handbook of positive organizational scholarship (pp. 178-189). Nueva York: Oxford University Press.

Boehm, J. K., \& Lyubomirsky, S. (2009). The promise of sustainable happiness. En C. R. Snyder \& S. J. Lopez (Eds.), Oxford handbook of positive psychology ( $2^{\mathrm{a}}$ ed., p. 667-677). Nueva York: Oxford University Press.

Brickman, P. C. B. (1978). Lottery winners and accident victims: Is 
happiness relative? Journal of Personality and Social Psychology, 36(8), 917-927.

Clark, A. D. (2008). Lags ad leads in life satisfaction: A test of the baseline hypothesis. The Economic Journal, 118(529), 222-243.

De Neve, J. E., Diener, E., Tay, L., $\&$ Xuereb, C. (2013). The objective benefits of subjective well being [CEP Discussion Papers, CEPDP1236]. Londres: Centre for Economic Performance, London School of Economics and Political Science.

Deci, E. L. (2008). Hedenia, eudaimonia, and well being: An introduction. Journal of Happiness Studies, 9(1), 1-11.

Delbecq, A. L. (1999). Christian spirituality and contemporary business leadership. Journal of Organizational Change Management. 12(4), 345-354.

DeSalvo, B. N., Bloser, N, Reynolds, K, He J., M. P. (2006). Mortality prediction with single general self-rated health question: A meta-analysis. Journal of General Internal Medicine. 21(3), 267-275.

Diener, E. (1999). Subjective well being. Three decades of progress. Psicological Bulletin.

Diener, E., \& Oishi, S. (2000). Money and happiness: Income and subjective well-being across nations. En E. Diener \& E. M. Suh
(Eds.), Culture and subjective well-being (p. 185-218). Cambridge: MIT Press.

Diener, E., \& Tay, L. (2012). A scientific review of the remarkable benefits of happiness for successful and healthy living (Report of the Well-Being Working Group, Royal Government of Bhutan: Report to the United Nations General Assembly, Well-Being and Happiness: A New Development Paradigm). Nueva York: Naciones Unidas.

Diener, E., Kesebir, P., \& Lucas, R. (2008). Benefits of accounts of well-being - for societies and for psychological science. Applied Psychology, 57, 37-53.

Diener, E., Kesebir, P., \& Tov, W. (2009). Happiness. En M. R. Leary\& R.H.Hoyle(Eds.),Handbook of individual differences in social behavior (pp. 147-160). Nueva York: Guilford Press.

Diener, E., Suh, E., Lucas, R., \& Smith,H.(1999). Subjectivewellbeing. Three decades of progress. PsicologicalBulletin, 125(2), 276302.

Elliot, A. J. (2002). Approach avoidance motivation in personality: Approach and avoidance temperaments and goals. Journal of personality and social psychology, 82(5), 804-818.

Fisher, C. (2010). Happiness at work. International Journal of Management Reviews, 12, 384-412. 
Folkman, S. (1997). Positive psychological states and coping with severe stress. Social Science \& Medicine, 45(8), 1207-1221.

Frederick, S., \& Loewenstein, G. (1999). Hedonic adaptation. En D. Kahneman, E. Diener, \& N. Schwarz (Eds.). Well-being: The foundations of hedonic psychology (p. 302-329). Nueva York: Russell Sage Foundation.

Fredrickson, B. (2001). The role of positive emotions in positive psychology: The broaden and build theory of positive emotions. American psychologist, 56(3), 218-226.

Gallagher, E. (2008). Social support and emotional intelligence as predictors of subjective wellbeing. Personality and individual Differences. 44, 1551-1561.

Gallant, P. S. (2007). Help or hindrance? How family and friends influence chronic illness self-management among older adults. Research on Aging, 29(5), 375409.

Gallup Healthways. (2013). State of global well being. Recuperado de http://www.well-beingindex.com/

Great Place to Work. (2013). Great place to work. What are the benefits. Recuperado de http:// www.greatplacetowork.com/ our-approach/what-are-the-benefits-great-workplaces
Green, L. (2001). Network correlates of social and emotional loneliness in young and older adults. Personality and social Psychology Bulleting, 27(3), 281-288.

Guariglia, O. (2002). Eudemonismo y virtud en la ética antigua: Aristóteles y los estoicos. Diálogos, 37(80), 7-50.

Huber, M. A. S., Knottnerus, J. A., Green, L., Van der Horst, H., Jadad, A. R., Kromhout, D., ... Smid, H. (2011). How should we define health? BMJ, 343(4163), 235-237.

Huppert, F. (2009). Psychological well-being: Evidence regarding its causes and consequences. Applied Psychology: Health and Well-Being, 1, 137-164.

Jadad, A. R. (2013). On living a long, healthy, and happy life, full of love, and with no regrets, until our last breath. Verhaltenstherapie, 23(4), 287-289.

Karakas, F. (2010). Spirituality and performance in organizations: A literature review. Journal of Business Ethics, 94(1), 89-106.

Kashdan, T. B., Biswas-Diener, R., \& King, L. A. (2008). Reconsidering happiness: The costs of distinguishing between hedonics and eudaimonia. The Journal of Positive Psychology, 3(4), 219233.

La Sociedad (2014). Teoría ética. Recuperado de http://www.oc- 
taedrotextos.com/praxis/pdf/ Teoria-etica.pdf

Locke, E. A. (1970). Job satisfaction and job performance: A theoretical analysis. Organizational Behavior and Human Performance, 5(5), 484-500.

Lucas, R. (2007). Adaptation and the set-point model of subjective well-being. Does happiness change after major life events? Current Directions in Psychological Science, 16(2), 75-79.

Lyubomirsky S., L. H. (1999). A measure of subjective happiness: Preliminary reliability and construct validation. Social Indicators Research, 46.2 137-155.

Lyubomirsky, S. K. (2005). The benefits of frequent positive affect: Does happiness lead tosuccess? Psychological bulletin, 131(6), 803.

Lyubomirsky, S. (2008). The how of happiness. Nueva York: Penguin Press.

Lyubomirsky, S., \& Sheldon, K. (2005). Pursuing happiness: The architecture of sustainable change. Review of General Psychology, 9(2), 111-131.

Lyubomirsky, S., King, L., \& Diener, E. (2005). The benefits of frequent positive affect: Does happiness lead to success? Pyschological Bulletin, 131(6), 803-855. Marcs, N. (2012). Happiness at work survey results for the Vitae
2012 Conference. Recuperado de https://www.google.com.co/ url $? \mathrm{sa}=\mathrm{t} \& \mathrm{rct}=\mathrm{j} \& \mathrm{q}=\&$ esrc $=\mathrm{s} \& \mathrm{~s}$ ource $=$ web $\& c d=1 \&$ cad $=$ rja $\& u a$ $\mathrm{ct}=8 \& \mathrm{ved}=0 \mathrm{CBwQFjAAahUK}$ EwiCp_rQ1ZHJAhWSth4KHQ E8Abg\&url $=\mathrm{https} \% 3 \mathrm{~A} \% 2 \mathrm{~F} \% 2$ Fwww.vitae.ac.uk\%2Fvitae-pu blications\%2Freports\%2Fhappi ness-at-work-report-vitae-2013. pdf $\% 2 \mathrm{~F} \% 40 \% 40$ download $\% 2$ Ffile\%2FHappiness-at-workreport-Vitae-2013.pdf\&usg=A FQjCNGF3afmVLDKCLg13c mXbmTT4ASYog\&sig2=EvmzZjHq1S6kBGPRQtJZA

Maslow, A. H. (1970). Motivation and personality. Nueva York: Harper \& Row.

Maslow, A. H. (2013). Toward a psychologyofbeing. Nueva York: Start Publishing.

Myers, D. G. (1995). Who is happy? Psychological Science, 6(1), 1019.

Nash, L. L. (2001). Church on Sunday, work on Monday: The challenge of fusing Christian values with business life. San Francisco: Jossey Bass.

Ostir, G. V, M. K. (2000). Emotional well-being predicts subsequent functional independence and survival. Geriatric Soc, 473-478.

Pavot, W., \& Diener, E. (1993). Review of the satisfaction with life scale. Psychological Assessment, 5(2), 164-172. 
Peterson, C. (2005). Orientations to happiness and life satisfaction: The full life versus the empty life. Journal of Happiness Studies, 6(1), 25-41.

Planells, A. (1988). Blaise Pascal y Jorge Luis Borges: las desavenencias entre el corazón y el intelecto. Bulleting Hipanique, 90(3), 321-343.

Punset, E. (2005). El viaje a la felicidad. Barcelona: Destino.

Rafael. (1509-1510). Aristóteles. Atenas: Escuela de Atenas.

Russell, J. A. (1980). A circumplex model of affect. Journal of Personality and Social Psychology, 39(6), 1161-1178.

Ryan, R. \& Deci, E. (2000). SelfDetermination theory and the facilitation of intrinsic motivation, social development and wellbeing. American Psychologist, 55(1), 68-78.

Ryan, R., Huta, V., \& Deci, E. (2008). Living well: A self-determination theory perspective on eudaimonia. Journal of Happiness Studies, 9(1), 139-170.

Ryff, C. \& Singer, B. (1996). Psychological well-being: Meaning, measurement and implications for psychotherapy research. Psychotherapy and psychosomatics, 65(1), 14-23.

Ryff, C. \& Singer, B. (2008). Know thyself and become what you are: A eudaimonic approach to psychological well-being. Journal of Happiness Studies, 9(1), 13-39.

Ryff, C. D. (1989). Happiness is everything, or is it? Explorations on the meaning of psychological well-being. Journal of Personality and Social Psychology, 57(6), 1069-1081.

Ryff, C. D. (1995). Psychological well-being in adult life. Current Directions in Psychological Science, 4(4), 99-104.

Seligman, M. (2000). Positive psychology: An introduction. American Psychologist, 55(1), 5-14.

Seligman, M. (2011). Learned optimism. Sydney:Random House.

Shadbolt, B., Barresi, J., \& Craft, P. (2002). Self- rated health as a predictor of survival among patients with advanced cancer. Journal of Clinical Oncology, 20(10), 2514-2519.

Stansfeld, S. A., Shipley, M. J., Head, J., Fuhrer, R., \& Kivimaki, M. (2013). Work characteristics and personal social support as determinants of subjective wellbeing. PLoS ONE, 8(11), 1-1.

Tellegen A., Lykken, D. T., Bouchard, T. J. Jr, Wilcox, K. J., Segal, N. L., \& Rich, S. (1988). Personality similarity in twins reared apart and together. Journal of Personality and Social Psychology, 54(6), 1031-1039.

Terner M., R. B. (2011). Chronic conditions more than age drive 
health system. Healthc $Q, 14, \quad$ anxiety and depressive disorders. 19-22. Journal of Abnormal Psycholo-

The Center of Bhutan Studies. gy, 97, 346-53.

(2010). Ophi. Obtenido de GNI and GNI index.

Wills, E. (2009). Spirituality and subjective well-being: Evidences for a new domain in the personal well-being index. Journal of The happiness initiative. Recuperado de http://www.happycounts.org/survey-methodology/

Ura, K. (2011). Explanation of the GNHIndex. Recuperadodewww. grossnationalhappiness Happiness Studies, 10(1), 49-69. World Health Organization. (1948). Definition. Recuperado de www. who.int/about/definition/en/ print.html

Vijayaraghavan, A. (2006). Aravind Hospital. India.

Watson D, Clark, L., \& Carey, G. (1988). Positive and negative affectivity and their relation to

Xanthopoulou, D. A. (2012). Everyday working life: Explaining within-person fluctuations in employee well-being. Human relations, 69(9), 1051-1069. 